\title{
Comment on Lobell et al "Climate Trends and Global Crop Production Since 1980".
}

Mikhail A. Semenov ${ }^{1 *} \&$ Peter R. Shewry ${ }^{2}$

${ }^{1}$ Centre for Mathematical and Computational Biology, ${ }^{2}$ Centre for Crop Genetic Improvement, Rothamsted Research, Harpenden, Herts, AL5 2JQ, UK

*corresponding author's email: mikhail.semenov@bbsrc.ac.uk

Lobel et al (ScienceXpress) analysed changes in global yields which can be attributed to climate change trend, and reported a $5.5 \%$ decline in global wheat production since 1980 . We have failed to confirm these results using a process-based crop model, which showed no decline in wheat yield since the 1950s at two European sites. The Lobel et al conclusions are not valid due to the limitations of the regression analysis used.

Lobel et al have used a regression model of yield responses to variation in the average temperature and precipitation in growing seasons since 1980 to demonstrate global decreases in yield which can be attributed to trend in climate for four major crops (maize, rice, wheat and soybean) ${ }^{1}$. The main conclusion of the study was that since 1980 the climatic trend has been responsible for reductions in global maize and wheat production by $3.8 \%$ and $5.5 \%$, respectively.

Regression models can be a useful tool when relationships between underplaying processes are unknown. However, cereal crop physiology has been well studied with a good understanding of crop responses to environmental factors ${ }^{2}$. This allows the development of process-based crop models which integrate the knowledge of crop growth and development using mathematical formalism and, therefore, have clear advantages over a simplistic regression approach. Crop models have been used by scientist for several decades and since the late 80s have been applied to predict the impacts of climate change on crop yields. They have been comprehensively tested against experimental datasets in diverse environments, including Free-Air $\mathrm{CO}_{2}$ Enrichment (FACE) experiments which mimic conditions of climate change on a field scale ${ }^{3,4}$. We have therefore conducted a simulation experiment using a crop model, Sirius ${ }^{5}$, at two European locations, Rothamsted, UK (RR) and Clermont-Ferrand, France (CF), in order to validate the conclusions of Lobel et al. Sirius has been calibrated for several modern wheat cultivars and was able to simulate accurately crop growth in a wide range of environments, including Europe, USA, NZ, Australia. We used daily weather data for period 1950-2008 for RR and 1955-2005 for CF and parameters for typical wheat cultivars, the UK cultivar Avalon for RR and the French cultivar Thesee for CF. To quantify only the effect of a climate trend on yield, Sirius was run with the constant ambient $\mathrm{CO}_{2}$ concentration of 350ppm. Using the two-samples (unpaired) t-test, we tested the 3 null hypothesis: $\mathrm{Y}_{1}=\mathrm{Y}_{2}, \mathrm{Y}_{1}<\mathrm{Y}_{2}$ and $\mathrm{Y}_{1}>\mathrm{Y}_{2}$, where $\mathrm{Y}_{1}$ 
and $\mathrm{Y}_{2}$ are mean yields for the first and last 20 years of available observed data at each site, respectively. The results are presented in Table 1.

Significant results (at 5\% significant level) were found at RR for two hypothesis that $\mathrm{Y}_{1}=\mathrm{Y}_{2}$ or $\mathrm{Y}_{1}>\mathrm{Y}_{2}$. These hypothesis must be rejected, leaving us with the conclusion that the yield has increased. For CF the results are inconclusive (none of hypothesis can be rejected), which means that we can safely assume that yield has not changed. These results directly contradict the conclusions of Lobell et al that wheat production in Europe (France was used a representative country) has declined by nearly 5\% since 1980 due to changes in the climate. Europe is the largest producer of wheat in the world with over $20 \%$ of world wheat production. If Lobell et al conclusions for Europe cannot be verified, results for other wheat-growing regions should also be treated with caution.

New crop cultivars will be required for a changing climate, which will be characterised in Europe by increased summer drought and heat stress by the 2050s. Crop modelling is a powerful tool to quantify potential threats to crops and hence identify targets for crop improvement ${ }^{6}$, with capabilities far beyond those of regression analysis. In a recent study ${ }^{7}$, we used Sirius combined with local-scale climate scenarios, based on the CMIP3 multi-model ensemble of global climate models, to predict impacts of extreme weather events (heat stress and severe drought) on wheat across several sites in Europe. It is well established that a short episode of high temperature around flowering can substantially reduce the wheat yield for heat-sensitive cultivars, because of reduction in the grain size and grain numbers ${ }^{8,9}$. Our analysis demonstrated that despite the lower summer precipitation predicted for 2050s across Europe, relative yield losses from drought will be smaller in the future, because wheat will mature earlier avoiding severe drought (Fig 1a). By contrast, the risk of heat stress around flowering will increase which may result in substantial yield losses for heat-sensitive cultivars commonly grown in northern Europe (Fig 1b). Having limited time and resources, crop scientists and breeders must select the most appropriate traits for crop improvement and should, therefore, focus on the development of wheat varieties, which are resistant to high temperature around flowering, rather than on developing varieties tolerant to drought, which may be required for other parts of the world.

Living and adapting to climate change is a major challenge and its impact on agriculture cannot be taken lightly. However, it important to be cautious in reporting "gloom and doom" scenarios to avoid providing fuel to the scepticism of a significant proportion of the population. 


\section{References}

1 Lobell, D. B., Schlenker, W. \& Costa-Roberts, J. Climate Trends and Global Crop Production Since 1980. ScienceExpress, (2011).

2 Porter, J. R. \& Semenov, M. A. Crop responses to climatic variation. Philosophical Transactions of the Royal Society B 360, 2021-2035, (2005).

3 Jamieson, P. D. et al. Modelling CO2 effects on wheat with varying nitrogen supplies. Agriculture, Ecosystems and Environment 82, 27-37, (2000).

4 Ewert, F. et al. Effects of elevated CO2 and drought on wheat: testing crop simulation models for different experimental and climatic conditions. Agriculture Ecosystems \& Environment 93, 249266, (2002).

5 Jamieson, P. D., Semenov, M. A., Brooking, I. R. \& Francis, G. S. Sirius: a mechanistic model of wheat response to environmental variation. European Journal of Agronomy 8, 161-179, (1998).

6 Semenov, M. A. \& Halford, N. G. Identifying target traits and molecular mechanisms for wheat breeding under a changing climate. Journal of Experimental Botany 60, 2791-2804, (2009).

7 Semenov, M. A. \& Shewry, P. R. Modelling predicts that heat stress, not drought, will increase vulnerability of wheat in Europe Nature Scientific Reports ((in press)).

8 Ferris, R., Ellis, R. H., Wheeler, T. R. \& Hadley, P. Effect of high temperature stress at anthesis on grain yield and biomass of field-grown crops of wheat. Annals of Botany 82, 631-639 (1998).

9 Wardlaw, I. F. \& Moncur, L. The response of wheat to high-temperature following anthesis . 1.The rate and duration of kernel filling. Aust. J. Plant Physiol. 22, 391-397 (1995). 
Table 1. Mean yields, Y1 and Y2, for the first and last 20 years of available observed data at each site and p-values for t-tests of null hypothesis that $\mathrm{Y}_{1}=\mathrm{Y}_{2}, \mathrm{Y}_{1}<\mathrm{Y}_{2}$ and $\mathrm{Y}_{1}>\mathrm{Y}_{2}$ at two European sites, RR Rothamsted, UK and CF - Clermont-Ferrand, France.

\begin{tabular}{cccccc}
\hline & & & \multicolumn{3}{c}{$\mathrm{p}$-values } \\
\cline { 4 - 5 } Site & $\mathrm{Y}_{1}, \mathrm{t} \mathrm{ha}^{-1}$ & $\mathrm{Y}_{2}, \mathrm{t} \mathrm{ha}^{-1}$ & $\mathrm{Y}_{1}=\mathrm{Y}_{2}$ & $\mathrm{Y}_{1}<\mathrm{Y}_{2}$ & $\mathrm{Y}_{1}>\mathrm{Y}_{2}$ \\
\hline $\mathrm{RR}$ & 9.384 & 9.797 & $\mathbf{0 . 0 2 9}$ & 0.985 & $\mathbf{0 . 0 1 5}$ \\
$\mathrm{CF}$ & 7.144 & 6.929 & 0.200 & 0.100 & 0.900 \\
\hline
\end{tabular}


Figure 1. (a) 95-perccentiles of yield losses due to water stress for 1960-1990 (black rectangles) and for the 2050(A1B) climate scenarios (box plots) at nine European sites (See Table SI.1 for details). Box plots represent uncertainty in predictions resulting from fifteen global climate models from the CMIP3 multi-model ensemble. Box boundaries indicate the 25 and 75-percentiles, the line within the box marks the median, whiskers below and above the box indicate the 10 and 90 -percentiles. (b) probability of maximum temperature exceeding thresholds of $27^{\circ} \mathrm{C}$ during flowering, which can substantially reduce yield for heat sensitive cultivars common in northern Europe (TR- Tylstrup, Denmark; WS- Warsaw, Poland; WA - Wageningen, the Netherlands; RR - Rothamsted, UK; MA Mannheim, Germany; DC - Debrecen, Hungary; CF - Clermont-Ferrand, France; MO - Montagnano, Italy; SL - Seville, Spain)

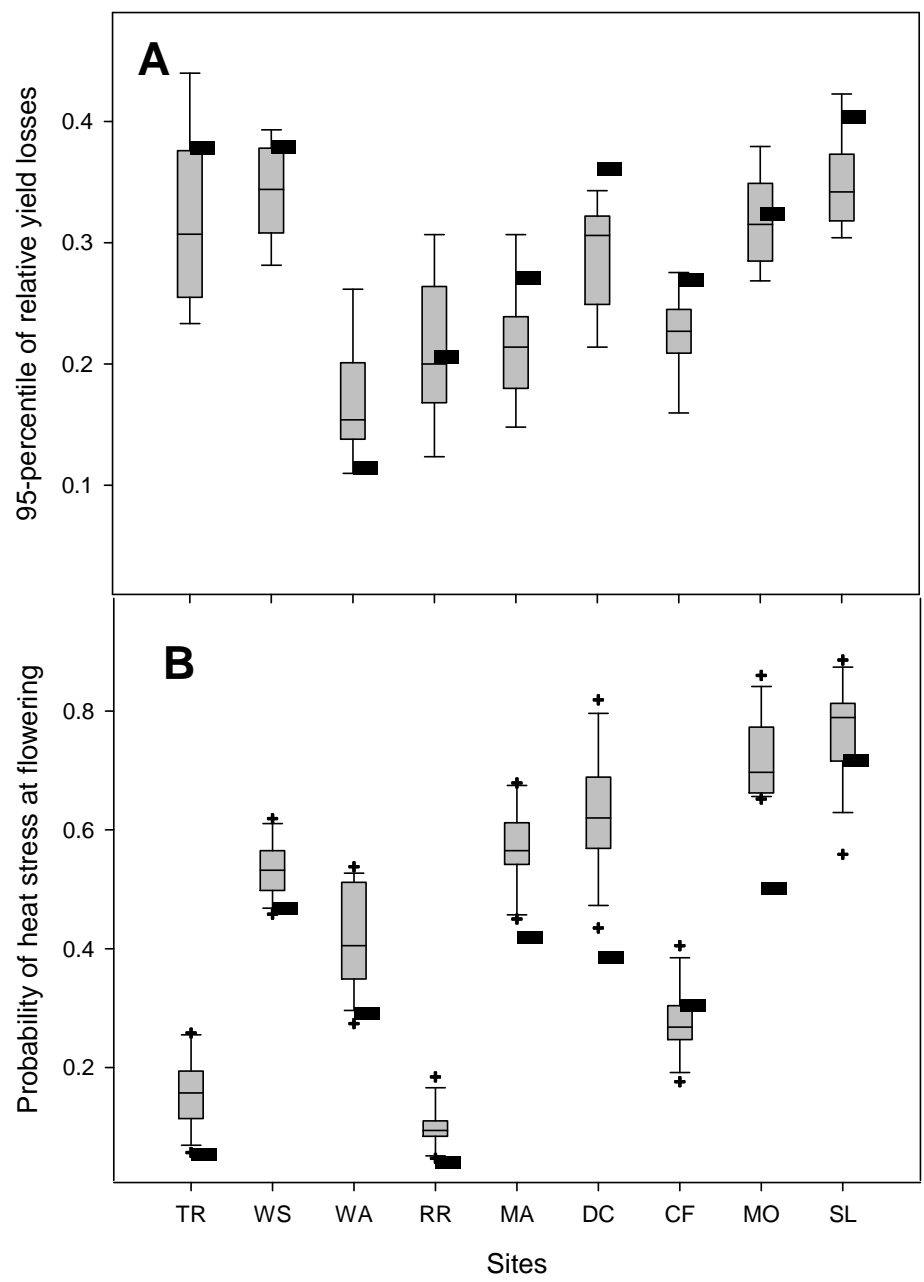

